\title{
Giải pháp hệ quản trị thông minh và hỗ trọ ra quyết định trong kế toán quản trị
}

\section{Business Intelligence solution and decision marking support in management accounting}

\author{
Nguyễn Thị Thu Phương ${ }^{1}$, Hồ Trung Thành ${ }^{1 *}$ \\ ${ }^{1}$ Trường Đại học Kinh Tế - Luật, Đại học Quốc gia Thành phố Hồ Chí Minh, Việt Nam \\ *Tác giả liên hệ, Email: thanhht@uel.edu.vn
}

THÔNG TIN

DOI: $10.46223 / \mathrm{HCMCOUJS}$. soci.vi.15.1.603.2020

Ngày nhận: 03/06/2020

Ngày nhận lại: 26/06/2020

Duyệt đăng: 26/06/2020

\section{Tù khóa:}

chỉ số đo lường hiệu suất, hệ quản trị thông minh, kế toán quản trị, ra quyết định

\section{TÓM TẮT}


Keywords:

KPIs, business intelligence, management accounting, desicion making

management and decision-making. Based on this, this study continuously opens a new interdisciplinary field of research related to management accounting and information technology systems. The study aims to propose models and solutions for BI systems and decision-making in management accounting integrated with BI solutions. The study model and proposal solutions are brought into a specific experimental case study through collecting data and analyzing KPIs for the performance of projects $1 \& 2$ at GS Company during the period of nearly 10 years-from October 2011 to May 2020. The analysis results are visualized within Dashboards (intelligent statements) helping managers make the decision quickly and effectively.

\section{Giới thiệu}

Ngày nay, các công ty trên thế giới cạnh tranh dựa trên sự phân tích. Việc quản trị thông tin đã trở thành mối quan tâm hàng đầu của các nhà quản trị hơn bao giờ hết, bởi vì nút thắt thành công của tổ chức không còn là vốn tài chính, nguyên vật liệu thô hoặc nguồn lực khác, mà là tài sản tri thức (Pirttimäki, 2007). Các công ty buộc phải sử dụng thông tin có hiệu quả hơn trước trong khi số lượng thông tin sẵn có cho nhà quản trị tăng chậm hơn số quyết định kinh doanh (Popovic, Turk, \& Jaklic, 2010), do đó hệ BI đã trở thành điều kiện tiên quyết cho lợi thế cạnh tranh. Hệ BI hỗ trợ người dùng nội bộ đánh giá, cải thiện và tối ưu hóa khả năng cũng như quy trình hoạt động của tổ chức. Hệ BI giúp thay đổi chiến lược điều hành từ kinh nghiệm chủ quan đến chiến lược điều hành dựa trên góc nhìn đa chiều bằng việc phân tích dữ liệu lịch sử và thông tin chính xác thu được từ cả bên trong và bên ngoài doanh nghiệp, giúp nhà quản trị đưa ra quyết định chính xác và kịp thời. Như vậy, KTQT có được những lợi ích đáng kể từ việc áp dụng hệ $\mathrm{BI}$ vào việc thu thập, lưu trữ, phân tích số liệu và trực quan hoá các báo cáo KTQT. Hệ BI được thiết kế để hỗ trợ cho việc ra quyết định trong KTQT là hoạt động hỗ trợ ra quyết định, như vậy có một mối liên hệ rõ ràng giữa hệ BI và KTQT (AICPA, 2013; Cokins, 2009; Maisel \& Cokins, 2014).

Tại Việt Nam, ngày càng nhiều doanh nghiệp quan tâm đến việc chuẩn hóa hệ thống quản trị dựa trên nền tảng CNTT đó là việc ứng dụng các hệ thống hoạch định nguồn lực doanh nghiệp (Enterprise Resource Planning System - ERP system) (Ho, Ho, Le, Le, \& Tran, 2016). Đầu ra của các hệ thống này là các dữ liệu sẵn sàng phục vụ việc phân tích. Tuy nhiên, việc khai phá các dữ liệu này chưa được chú trọng nên chỉ dừng ở các yêu cầu kết xuất báo cáo nghiệp vụ đơn thuần của các phòng ban. Bên cạnh đó khá nhiều thông tin quan trọng cho người ra quyết định và lập kế hoạch chiến lược đã bị bỏ qua do thiếu công cụ tổng hợp, phân tích dữ liệu và trực quan hóa. Và vấn đề của Công ty GS cũng không nằm ngoài những hạn chế trên. Xuất phát từ thực tế tại công ty, rõ ràng nhận thấy được rằng $\mathrm{BI}$ cần cho mọi tổ chức, giúp doanh nghiệp dễ dàng có được ngay các thông tin và tri thức để ra quyết định.

Để giải quyết tồn tại trên, trong bài báo này, mục tiêu nghiên cứu là đề xuất mô hình và giải pháp hệ $\mathrm{BI}$, ra quyết định trong KTQT tích hợp với giải pháp BI. Từ đó mô hình nghiên 
cứu và giải pháp đề xuất được đưa vào thực nghiệm trường hợp cụ thể tại công ty GS. Kết quả phân tích được trực quan hóa trên các dashboard giúp nhà quản trị ra quyết định nhanh chóng và hiệu quả hơn.

Phần còn lại của bài báo được trình bày theo cấu trúc như sau: Phần 2 là cơ sở lý thuyết và các nghiên cứu liên quan đến hệ BI hỗ trợ ra quyết định trong KTQT. Khảo sát mô hình hệ BI hỗ trợ ra quyết định; Phân tích hiện trạng và đề xuất giải pháp phù hợp dựa trên nền tảng HTTT được trình bày ở Phần 3 . Kết quả nghiên cứu gồm hệ thống báo cáo về tài chính trong KTQT; Phân tích và trực quan dữ liệu sẽ được đề cập trong phần 4 . Cuối cùng là Phần 5 với kết luận và hướng phát triển.

\section{Cơ sở lý thuyết và các nghiên cứu liên quan}

\subsection{Khái niệm hệ BI}

Hệ $\mathrm{BI}$ là một quá trình và là chức năng tổ chức tích cực tham gia vào chuỗi giá trị thông tin bằng cách xử lý dữ liệu và thông tin thành trí thông minh có thể được khai thác trên tất cả các cấp của một tổ chức dẫn đến các quyết định kinh doanh tốt hơn và kịp thời (Clark, Jones, \& Armstrong, 2007; Kaario \& Peltola, 2008). Phân tích dữ liệu (analytics), kho dữ liệu (data warehouse), báo biểu thông minh (dashboard) là ba chức năng chính của một giải pháp BI. BI bao gồm thông tin về xu hướng và mô hình quan trọng cũng như mối quan hệ giữa hành vi của khách hàng và tổ chức, biểu thị một số nguyên nhân kết quả nhất định và dự đoán những thay đổi. Những thay đổi này có thể chỉ ra những cơ hội và mối đe dọa mới trong kinh doanh, điều này thúc đẩy quá trình ra quyết định chiến lược (Pirttimäki, 2007). Các ứng dụng của BI cung cấp cho người dùng khả năng dễ dàng trích xuất dữ liệu từ một hoặc nhiều nguồn và chủ đề khác nhau (Jonathan, 2000). Ngoài ra, BI còn cung cấp cho người dùng khả năng phân tích đa chiều hỗ trợ cho nhà quản trị ra quyết định tốt hơn. Trong nghiên cứu của Olivia (2009) về sự phát triển của lý thuyết hệ thống thông tin và hệ hỗ trợ ra quyết định, tác giả đã đưa ra một đị̣h nghĩa khá phù hợp để mô tả về bản chất các thành phần của một hệ BI. BI là khái niệm nói về một kết hợp các cơ sở lý thuyết, phương pháp, kiến trúc và công nghệ nhằm khai thác những thông tin hữu ích từ dữ liệu sơ cấp phát sinh trong quá trình hoạt động của doanh nghiệp. Chaudhuri, Dayal, và Narasayy (2011) định nghĩa hệ BI là công nghệ và quy trình phân tích dữ liệu và trình bày thông tin giúp nhà quản trị ra quyết định tốt hơn. Hệ BI bao gồm nhiều công nghệ và phương pháp cho phép các tổ chức thu thập dữ liệu bên trong và bên ngoài doanh nghiệp để phân tích, phát triển và truy vấn dữ liệu, tạo báo cáo, bảng điều khiển và trực quan hóa dữ liệu để cung cấp kết quả cho người dùng cuối cùng.

Như vậy, hệ BI là một dạng thức của hệ hỗ trợ ra quyết định, hệ thống này phục vụ cho việc ra quyết định trong các hoạt động kinh doanh của doanh nghiệp bằng cách phân tích, biểu diễn và khai phá các thông tin hữu ích từ dữ liệu. Bên cạnh đó, hệ $\mathrm{BI}$ còn giúp các nhà quản trị có cái nhìn bao quát được tình hình kinh doanh từ quá khứ đến hiện tại; những thuận lợi và khó khăn của doanh nghiệp trong bối cảnh nền kinh tế thị trường, từ đó xây dựng một chiến lược linh hoạt và hiệu quả cho doanh nghiệp trong tương lai. Hệ BI đơn giản được xem là sự kết hợp của 3 thành phần chính như sau: (i) kho dữ liệu (kho chứa dữ liệu tổng hợp của doanh nghiệp); (ii) Khai phá dữ liệu (sử dụng các kỹ thuật để khai phá dữ liệu như phân loại, phân cụm, phát hiện luật kết hợp và dự đoán); và (iii) Phân tích kinh doanh (các nhà quản trị đưa ra những quyết định chiến lược đối với hoạt động kinh doanh của doanh nghiệp). Các giải pháp của hệ BI hiện đại, tiên tiến hơn về mặt công nghệ so với giải pháp Hệ hỗ trợ quyết định (DSS), Hệ thông tin tổ chức 
(EIS) và Hệ thông tin quản lý (MIS) trước đó. Đặc biệt về khả năng sử dụng, quản lý dữ liệu, bao gồm loại dữ liệu, sự tinh vi của kỹ thuật phân tích và trực quan hóa/khả năng báo cáo (Chen, Chiang, \& Storey, 2012).

\subsection{Lý thuyết về nghiên cứu kế toán quản trị}

Kế toán quản trị là một bộ phận cấu thành của hệ thống thông tin kế toán nói chung trong các doanh nghiệp. Trong nền kinh tế thị trường, sự cạnh tranh giữa các doanh nghiệp, tập đoàn, quốc gia là nguyên nhân dẫn đến sự phát triển của KTQT. Thông tin KTQT là công cụ hữu hiệu để các nhà quản trị đưa ra quyết định điều hành mọi hoạt động sản xuất kinh doanh của doanh nghiệp nhằm hướng tới mục tiêu tối đa hóa lợi nhuận. Việc nghiên cứu KTQT được xem xét từ nhiều quan điểm và góc độ khác nhau thông qua các nghiên cứu của Kaplan (1994); Bouquin (2010); Hiệp hội kế toán viên quản trị Hoa Kỳ, Thông tư 53/2006/TT-BTC của Bộ Tài chính.

Các nghiên cứu trên tuy có sự khác nhau về hình thức, song đều có định nghĩa cơ bản giống nhau: KTQT là một bộ phận cấu thành trong hệ thống kế toán của các tổ chức hoạt động và là cơ sở khoa học để đưa ra mọi quyết định kinh doanh. Do vậy KTQT đóng vai trò quan trọng, không thể thiếu được trong các doanh nghiệp kinh doanh theo cơ chế thị trường. Thông tin KTQT giúp cho nhà quản trị thực hiện chức năng quản trị doanh nghiệp: Lập kế hoạch; tổ chức thực hiện; kiểm tra; đánh giá và ra quyết định.

Thông tin kế toán thường là nhân tố chính trong việc ra quyết định của nhà quản trị. Điều này được thể hiện rất rõ qua bản chất của thông tin kế toán là nguồn tin mang tính chính xác, kịp thời, hữu ích nhất so với thông tin từ những lĩnh vực chuyên ngành khác (Q. T. Nguyen, 2017). Để ra quyết định ngắn hạn hay dài hạn, các nhà quản trị phải lựa chọn hợp lý trong nhiều phương án khác nhau. Tất cả các quyết định đều có nền tảng từ thông tin và phần lớn thông tin do KTQT cung cấp.

Lý thuyết bất định (Contingency theory) là một cách tiếp cận để nghiên cứu hành vi tổ chức, trong đó đưa ra những giải thích về các yếu tố ngữ cảnh ảnh hưởng như thế nào đến việc thiết kế tổ chức (Otley, 1980). Lý thuyết bất định được phát triển từ lý thuyết tổ chức và được áp dụng trong nghiên cứu KTQT. Các nhà nghiên cứu kế toán đã tập trung tìm hiểu ảnh hưởng của các yếu tố ngữ cảnh truyền thống như môi trường bên ngoài, công nghệ, cấu trúc tổ chức, quy mô tổ chức (Otley, 1980; Waterhouse \& Tiessen, 1978), yếu tố văn hóa (Harrison, 1992; O'Connor, 1995) và chiến lược (Langfield-Smith, 2006) đến việc thiết kế và sử dụng hệ thống KTQT. Bên cạnh đó công nghệ là một biến ảnh hưởng lớn đến nghiên cứu KTQT. Những thay đổi về công nghệ được sử dụng bởi các tổ chức thường dẫn đến những thay đổi trong các yêu cầu của tổ chức về KTQT. Trong trường hợp này, lý thuyết bất định có thể dùng để giải thích nhân tố môi trường bên ngoài là việc ứng dụng công nghệ hệ BI có tác động/hỗ trợ cho thông tin KTQT của đơn vị.

\subsection{Chỉ số đo lường hiệu suất (KPI)}

KPI viết tắt từ Key Performance Indicator (tạm dịch Chỉ số đo lường hiệu suất) là một tập hợp các phép đo tập trung vào những khía cạnh hoạt động tổ chức mà được coi là quan trọng nhất cho sự thành công ở hiện tại và trong tương lai (Parmenter, 2009). KPIs nằm trong bộ các chỉ số đo lường hiệu quả, cùng với KRIs (Key result indicators - Các chỉ số kết quả cốt yếu), PIs (Performance indicators - Các chỉ số hiệu suất) và RIs (Result indicators - Các chỉ số kết quả). KPIs được sử dụng rất rộng rãi trên thế giới như là một phương thức hữu hiệu để đo lường hiệu suất công tác thông qua việc thiết lập được một hệ thống các thước đo hiệu suất. 
Trong lĩnh vực xây dựng, trên thế giới KPIs được ứng dụng khá rộng rãi để đo lường hiệu quả trên công trường (Salminen, 2005), đo năng suất lao động (Cox, Issa, \& Ahrens, 2003), đo lường tổng thể thành công của các dự án PPP (Ogunsanmi, 2013)... Tại Việt Nam, trong bối cảnh thiếu các chỉ số định lượng đánh giá hiệu quả của các doanh nghiệp xây dựng thì KPIs chính là sự bổ sung thực sự cần thiết. Nhận thấy, những lợi ích tiềm năng cho doanh nghiệp ngành xây dựng khi áp dụng KPIs: nhìn ra các vấn đề đang tồn tại, chỉ ra điểm mạnh, điểm yếu; tiết kiệm chi phí; bổ sung các tiêu chí chấm thầu; thu hút khách hàng tiềm năng; hồ trợ triển khai Xây dựng Tinh gọn (B. N. Nguyen, 2017).

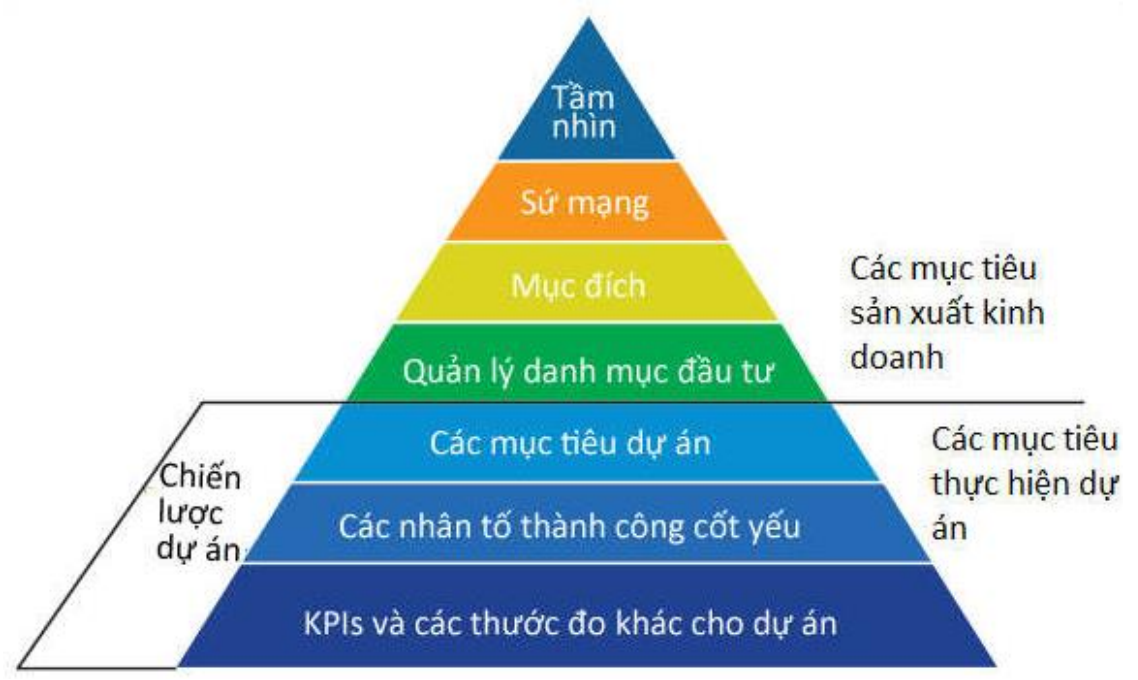

Hình 1. Vị trí của KPIs trong quản trị chiến lược (Kerzner, 2011)

\subsection{Các nghiên cúu liên quan và khoảng trống tri thức}

Nghiên cứu của Pall và Ogan (2018) đã thống kê 5 lĩnh vực nghiên cứu trọng tâm về hệ BI trong KTQT từ năm 2005 đến 2015. Khuôn mẫu này được đánh giá là tổng quan nhất về sự tác động của hệ BI trong KTQT. Mô hình được mô tả dưới đây:

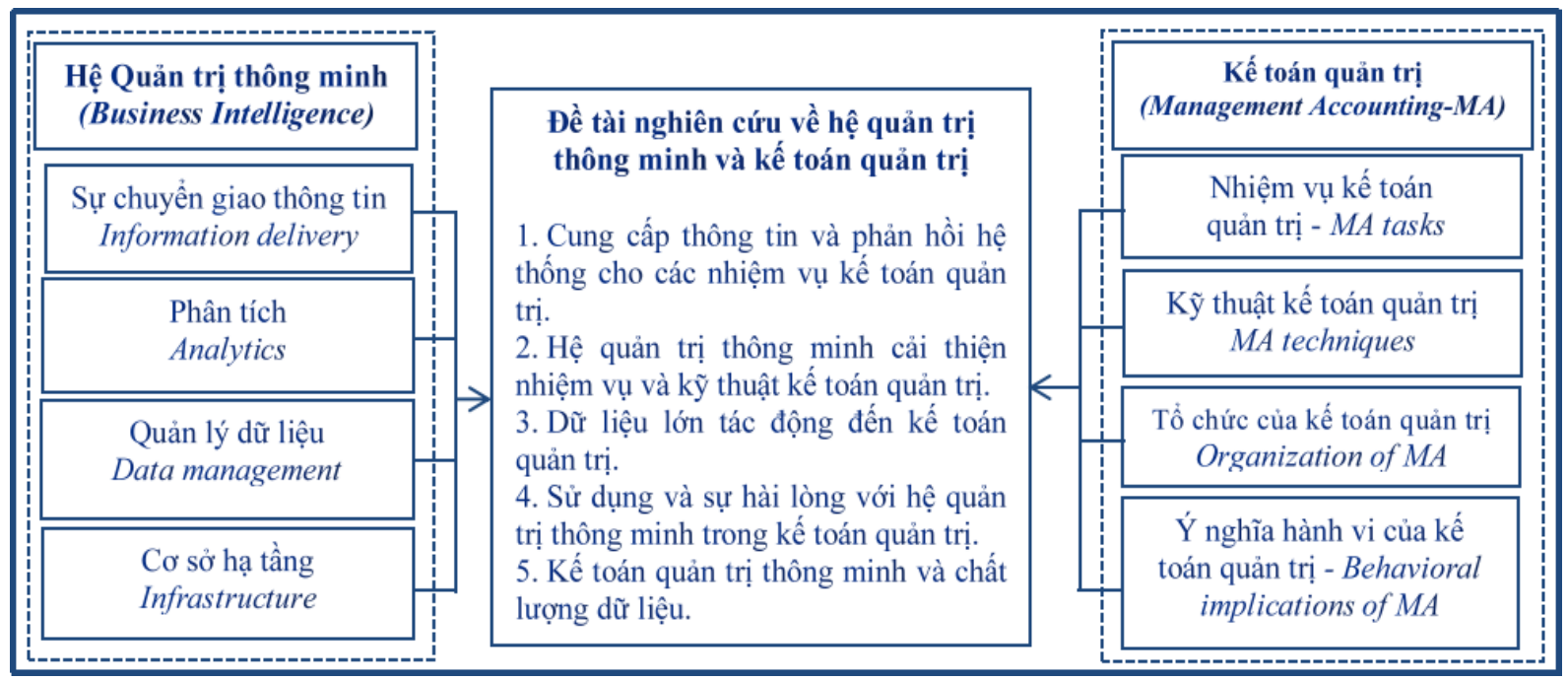

Hình 2. Mô hình 5 lĩnh vực trọng tâm trong nghiên cứu về hệ BI và KTQT (Pall \& Ogan, 2018) 


\section{a. Hệ BI cung cấp thông tin và phản hồi hệ thống cho các nhiệm vụ KTQT}

Nhiệm vụ của KTQT bao gồm lập kế hoạch, đo lường hiệu suất, quản lý chi phí, xử lý giao dịch, báo cáo và hỗ trợ ra quyết định. Như vậy, hệ $\mathrm{BI}$ ảnh hưởng đến nhiệm vụ hỗ trợ ra quyết định và cách trình bày thông tin liên quan đến người ra quyết định (Atkinson, Kaplan, \& Young, 2011; Booth, Matolcsy, \& Wieder, 2000). Trong thực tế, KTQT sẽ không còn là nhà thiết kế hệ thống báo cáo quản trị. Thay vào đó, KTQT sẽ (i) đóng vai trò tư vấn cho người dùng cuối cùng, hỗ trợ họ trong việc lựa chọn và giải thích dữ liệu liên quan đến quyết định; và (ii) đóng vai trò hỗ trợ nhân viên CNTT trong việc lựa chọn các tính năng của giải pháp BI cho người dùng cuối cùng, để tìm ra sự phù hợp nhất giữa các tính năng của hệ thống BI với các yêu cầu và đặc điểm của người dùng trong một tổ chức. Khi CNTT thay đổi các nhiệm vụ KTQT thì giá trị của việc tạo ra tri thức từ dữ liệu tăng lên. Để thực hiện các công việc như phân tích chi phí, lợi nhuận, doanh thu và kiểm soát quản lý, KTQT cần được đào tạo về phương pháp phân tích, giải thích và trình bày dữ liệu cũng như kết hợp với các chức năng phân tích (Phillips, 2013).

Hiện nay, ngày càng nhiều doanh nghiệp đã nhận thức được tầm quan trọng của phân tích và trực quan hóa dữ liệu cho các nhiệm vụ của KTQT. Trực quan hóa dữ liệu được công nhận như là một phương thức hiệu quả để chuyển đổi dữ liệu kinh doanh sang những thông tin hữu ích, giúp nhà lãnh đạo ra những quyết định kịp thời và mang lại những lợi ích lớn cho doanh nghiệp. Mặc dù đã có nhiều nghiên cứu trước đây tập trung vào việc phân tích dữ liệu với biểu đồ dữ liệu dạng số, nhưng việc sử dụng và hiệu quả của các kỹ thuật trực quan hóa dữ liệu trong KTQT cho nguồn dữ liệu vẫn chưa được khám phá. Đặc biệt là, các kỹ thuật trực quan hóa cho dữ liệu có hữu ích gì cho việc lập kế hoạch và kiểm soát nội bộ hay không? Ngoài ra, những kỹ thuật trực quan nào phù hợp cho các kỹ thuật khai phá dữ liệu phức tạp. Tóm lại, cho đến nay có một khoảng trống tri thức và thiếu những bằng chứng thực nghiệm về mức độ sử dụng và hiệu quả của các kỹ thuật phân tích và trực quan hóa dữ liệu của hệ BI trong KTQT. Đây là điểm hạn chế của các nghiên cứu trước và gợi ý của nghiên cứu này cho những nghiên cứu kế tiếp.

\section{b. Hệ BI cải thiện các nhiệm vụ và kỹ thuật của KTQT}

BI cung cấp hệ hỗ trợ ra quyết định Data-centric (ứng dụng cơ sở dữ liệu) giúp KTQT trong việc lập kế hoạch, đo lường hiệu suất và kỹ thuật quản lý chi phí (Volitich \& Ruppert, 2012). Các kỹ thuật KTQT Data-driven (Điều hướng dữ liệu) giúp cải thiện sự suy luận, dự đoán và sự đảm bảo, đồng thời các kỹ thuật này còn có khả năng làm tăng tải nhận thức và định kiến nhận thức (Schneider, Jun Dai, Janvrin, Ajayi, \& Raschke, 2015). Nghĩa là làm tăng khả năng tiếp nhận một lượng lớn thông tin phải xử lý trong một thời gian ngắn. Để khắc phục những hạn chế của $\mathrm{BI}$ và định kiến nhận thức thì đòi hỏi các tổ chức và đặc biệt là KTQT phải hiểu rõ hơn về (i) quá trình ra quyết định, (ii) bản chất của nhiệm vụ và (iii) yêu cầu của người dùng.

\section{c. Kế toán quản trị và hành vi}

Cho đến nay có tương đối ít nghiên cứu về ứng dụng BI trong KTQT có ảnh hưởng đến hành vi ra quyết định của nhà quản trị. Để hệ $\mathrm{BI}$ có tác động đến hành vi thì các tổ chức (cụ thể là nhà quản trị) cần có khả năng ứng dụng (Elbashir, Collier, \& Sutton, 2011). Nghĩa là, sự hài lòng của người dùng cao hơn dẫn đến việc sử dụng hệ thống được cải thiện và chất lượng quyết định được cải thiện. Sự thành công của hệ thống phụ thuộc vào chính hệ thống đó và kiến thức của người dùng về hệ thống. Do đó, đào tạo người dùng về chức năng BI trong KTQT là điều cần thiết (Deng \& Chi, 2012). 


\section{d. Hệ BI và chất lựng dĩ liệu}

Tính kịp thời và sự cần thiết của việc sử dụng hệ BI là quan trọng hàng đầu (Neely \& Cook, 2011). Điều này có nghĩa là nhà quản trị cần những thông tin kịp thời trong một khoảng thời gian cụ thể để đưa ra quyết định. Thông tin có thể lấy từ nhiều nguồn dữ liệu khác nhau do vậy không thể đảm bảo chắc chắn rằng dữ liệu thu thập được phù hợp với tiêu chí chất lượng. Do vậy tác giả đề xuất trong tương lai các nghiên cứu về KTQT nên tập trung vào việc sử dụng thông tin được phân tích đa chiều để ra quyết định hiệu quả, bao gồm các lĩnh vực như hệ BI, hệ hỗ trợ ra quyết định và trực quan hóa dữ liệu.

Kết luận, hướng nghiên cứu liên ngành giữa HTTT và KTQT là hướng nghiên cứu mới và mang tính ứng dụng thực tế. Đây chính là điểm nổi bật của nghiên cứu này. Cho đến nay hệ $\mathrm{BI}$ ngày càng trở nên cần thiết cho các nhà quản trị cấp cao của bất kỳ tổ chức nào để trực quan hóa, phân tích và chuẩn bị kế hoạch chiến lược cho tương lai (Gounder, Iyer, \& Mazyad, 2016). Cơ sở lý thuyết và các nghiên cứu có liên quan về hệ BI hỗ trợ ra quyết định trong KTQT đã được nhiều tác giả nghiên cứu và còn nhiều khoảng trống tri thức cần tiếp tục được khám phá.

\section{Khảo sát mô hình và đề xuất giải pháp}

\subsection{Khảo sát mô hình hệ BI hỗ trọ’ ra quyết định}

Cho tới nay đã nhiều nghiên cứu về hệ BI, trong đó mô hình hệ BI hỗ trợ ra quyết định của Laudon và Laudon (2018) được đánh giá là đầy đủ các nhân tố. Tác giả nhận định rằng: Môi trường hệ $\mathrm{BI}$ bao gồm 6 nhân tố đó là: Dữ liệu từ môi trường kinh doanh; Hạ tầng hệ $\mathrm{BI}$; Công cụ phân tích kinh doanh; Người dùng và phương pháp quản lý; Nền tảng phân phối (MIS, DSS, ESS) và Giao diện người dùng (Công cụ trực quan hóa dữ liệu). Mối quan hệ giữa các nhân tố được thể hiện qua mô hình (Hình 3) sau đây:

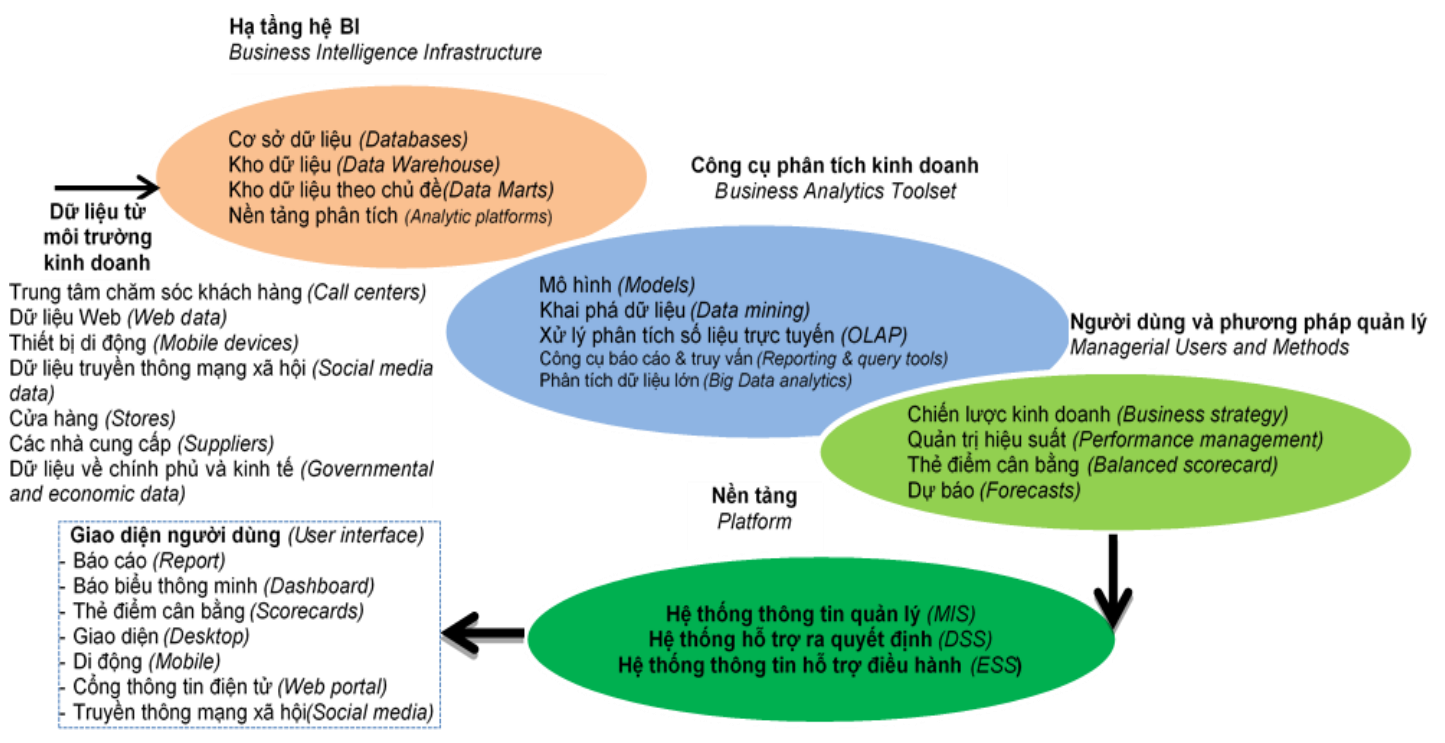

Hình 3. Mô hình hệ BI hỗ trợ ra quyết định (Laudon \& Laudon, 2018) 


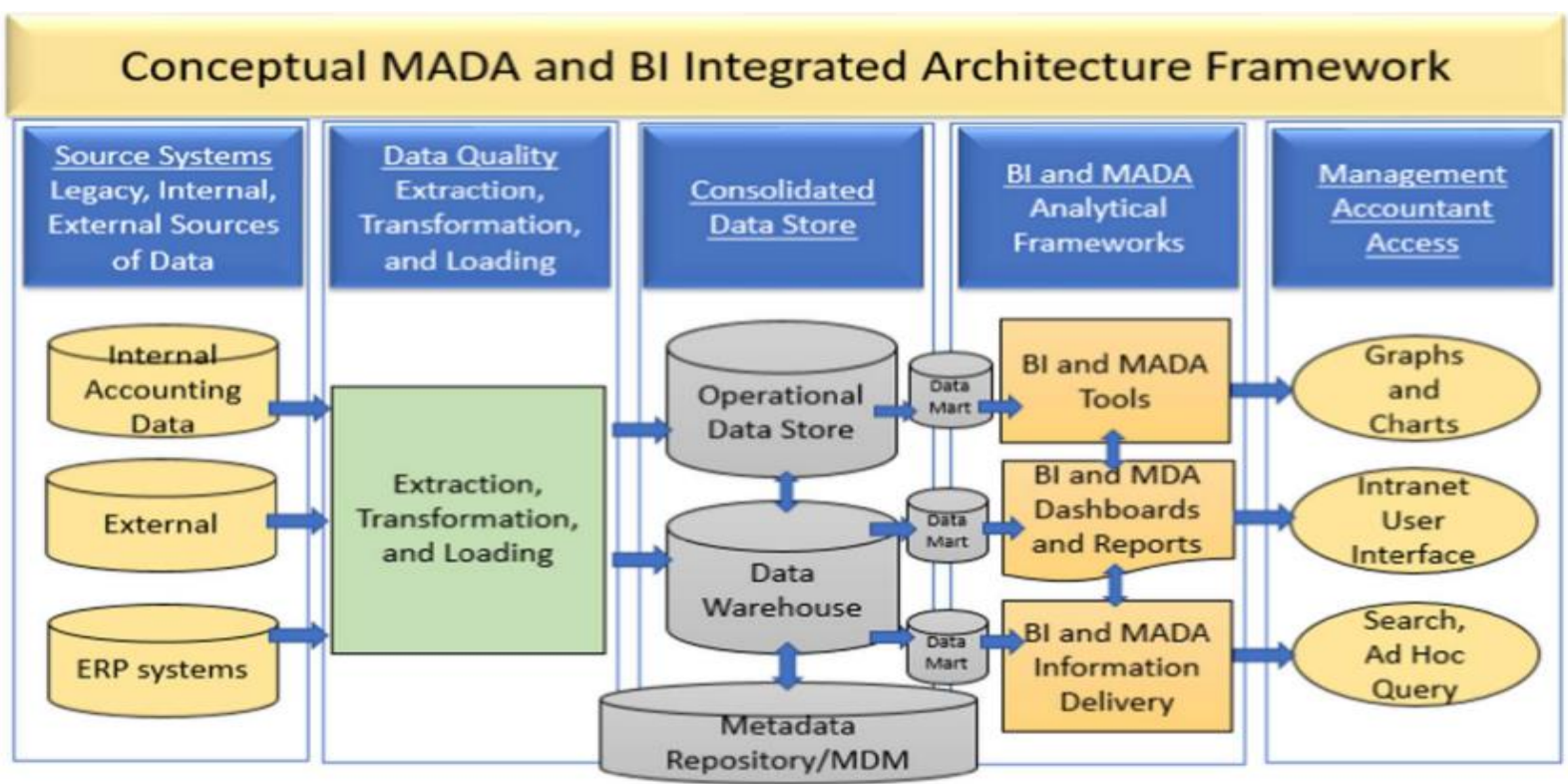

Hình 4. Khung khái niệm phân tích dữ liệu KTQT và tích hợp hệ BI (Appelbaum, Kogan, Vasarhelyi, \& Yan, 2017)

Trong nghiên cứu của Appelbaum và cộng sự (2017) về sự tác động của phân tích kinh doanh và hệ thống doanh nghiệp trong KTQT, nhóm tác giả đã xây dựng một khung phân tích dữ liệu KTQT (Hình 4) như một cách để KTQT tận dụng các phát triển mới trong hệ thống doanh nghiệp, sử dụng các phân tích mô tả, dự đoán và phân tích để đo lường hiệu suất từ các thẻ điểm cân bằng, tức là tài chính, khách hàng, quy trình nội bộ, học tập và tăng trưởng. Tác giả nhận định để thành công khung phân tích dữ liệu KTQT phải trở thành một thành phần của hệ thống BI toàn diện của một doanh nghiệp. Tổng quan nghiên cứu cho thấy, mô hình của Appelbaum và cộng sự (2017) có thể được coi là mô hình chung nhất về nghiên cứu và ứng dụng hệ BI hỗ trợ ra quyết định trong KTQT. Mô hình này cho phép tiếp cận toàn diện các nhân tố của hệ $\mathrm{BI}$ hỗ trợ ra quyết định, đảm bảo ứng dụng giải pháp dựa trên nền tảng hệ thống thông tin.

\subsection{Phân tích hiện trạng và đề xuất giải pháp hệ BI hỗ trọ’ ra quyết định trong KTQT tại Công ty $G S$}

\subsubsection{Giới thiệu công ty $G S$}

Công ty GS được thành lập vào năm 1969 với trụ sở chính đặt tại Hàn Quốc. Lĩnh vực hoạt động: Xây dựng công trình, xây dựng dân dụng, công nghệ, môi trường, dầu khí và nhiều lĩnh vực khác. Công ty GS gia nhập thị trường Việt Nam từ năm 2004 với hai chi nhánh văn phòng đại diện chính tại Thành phố Hà Nội và Thành phố Hồ Chí Minh. Công ty đã và đang thực hiện nhiều dự án tại Việt Nam.

\subsubsection{Thu thập dĩ liệu}

Dữ liệu được tác giả tiến hành nghiên cứu định tính và định lượng. Phương pháp nghiên cứu định tính được đánh giá là phù hợp trong nghiên cứu này. Bởi các quyết định chiến lược của nhà quản trị là loại quyết định định tính, dựa trên tư duy chủ quan của nhà quản trị liên quan đến mục tiêu của doanh nghiệp. Do vậy tác giả sử dụng phương pháp phỏng vấn $(\mathrm{D}$. T. 
Nguyen, 2013) với số lượng là 4 người. Người được phỏng vấn là Giám đốc dự án, nhà quản trị cấp cao, chuyên viên IT, Kế toán trưởng của công ty, độ tuổi từ 35 đến 52 tuổi, trình độ cử nhân, có kinh nghiệm làm việc tại công ty trên 10 năm. Số lượng mẫu này được đánh giá là phù hợp, bởi trong nghiên cứu định tính, số lượng mẫu phụ thuộc vào đặc điểm nghiên cứu vì vậy nên để cho các nhà nghiên cứu quyết định (Patton, 1990; Romano, 1989). Hơn nữa, nếu số lượng mẫu thấp hơn 4 thì rất khó để tạo ra lý thuyết và kết quả thực nghiệm có thể sẽ không thuyết phục (Eisenhardt, 1989). Kết quả ý kiến của người tham gia thảo luận được tác giả ghi nhận và phân loại để tìm hiểu về nhu cầu sử dụng thông tin KTQT trong quá trình ra quyết định của nhà quản trị, từ đó làm cơ sở đề xuất để xây dựng các chỉ số KPIs và giải pháp hệ BI.

Trong nghiên cứu định lượng, nguồn dữ liệu được tác giả thu thập từ các nghiệp vụ kế toán tài chính (KTTC), KTQT của hai dự án 1 và 2 tại Thành phố Hồ Chí Minh trong thời gian từ tháng 10/2011 đến tháng $5 / 2020$ (Bảng 1 ).

\section{Bảng 1}

Kết quả phân tích độ tin cậy các thang đo

\begin{tabular}{|c|c|c|}
\hline Năm & Số giao dịch & Phòng ban \\
\hline 2011 & 202 & BP Tài chính kế toán \\
\hline 2012 & 1.796 & BP Tài chính kế toán \\
\hline 2013 & 3.080 & BP Tài chính kế toán \\
\hline 2014 & 3.456 & BP Tài chính kế toán \\
\hline 2015 & 3.707 & BP Tài chính kế toán \\
\hline 2016 & 3.755 & BP Tài chính kế toán \\
\hline 2017 & 3.002 & BP Tài chính kế toán \\
\hline 2018 & 2.811 & BP Tài chính kế toán \\
\hline 2019 & 2.572 & BP Tài chính kế toán \\
\hline $05 / 2020$ & 1.046 & BP Tài chính kế toán \\
\hline Tổng & $\mathbf{2 5 . 4 2 7}$ & \\
\hline
\end{tabular}

Nguồn: BP Tài chính kế toán; dữ liệu này không ngoài mục đích phục vụ nghiên cứu và triển khai giải pháp tại Công ty GS

Trong đó, dự án số 1 xây dựng tuyến cáp ngầm mới để thay thế cho các đoạn tuyến đường dây trên không $220 \mathrm{kV}, 110 \mathrm{kV}$ hiện hữu di dời ra khỏi khu đất Nhà Bè Metrocity. Dự án số 2 thi công các tuyến đường sắt đô thị, dự án này đóng vai trò quan trọng trong việc giải quyết tình trạng ùn tắc giao thông và ô nhiễm môi trường, đóng góp vào sự phát triển đô thị hiện đại, văn minh nhờ vào những ưu thế của hệ thống Metro là vận chuyển nhanh và tự động khi tích hợp với các hệ thống xe buýt và các loại hình giao thông khác. Các nghiệp vụ kế toán ghi nhận trong dự án số 1 và 2 là tương đồng nhau, dữ diệu đồng nhất, phù hợp để thống kê chung và được tích hợp vào nguồn dữ liệu hợp nhất dạng cộng gộp số lượng giao dịch. Dữ liệu thu thập được tích hợp vào hệ $\mathrm{BI}$ để phân tích và trực quan hóa kết quả phân tích dữ liệu bằng dashboard. 
Phần kỹ thuật sẽ sử dụng hệ thống phân tích dữ liệu Tableau. Kết quả nghiên cứu được triển khai ứng dụng cho trường hợp cụ thể tại bộ phận tài chính kế toán của doanh nghiệp.

Nguồn dữ liệu này đang được lưu trữ ở nhiều định dạng khác nhau nên trước tiên cần chuyển dạng và tích hợp vào "Nguồn dữ liệu hợp nhất" để tiến hành phân tích và trực quan hóa với giải pháp BI được nghiên cứu đề xuất (Hình 5).

\subsubsection{Xây dựng mô hình}

Kết quả nghiên cứu định tính cho thấy, thực trạng dữ liệu đã được tích lũy từ nhiều năm cho đến nay vẫn chưa có công cụ hay cách thức nào để có thể khai thác tri thức từ lượng dữ liệu này. Dữ liệu khá lớn nhưng lại thiếu thông tin hữu ích phục vụ hoạt động ra quyết định và thiếu công cụ phân tích trực quan trong quản lý điều hành. Phòng tài chính kế toán và phòng IT đang quá tải với công việc kết xuất báo cáo tổng hợp, mà phần lớn các báo cáo tổng hợp này chủ yếu dựa trên excel không đủ để đáp ứng nhu cầu thông tin cho nhà quản trị bởi dữ liệu quá lớn. Bên cạnh đó, dữ liệu của công ty được khai thác từ nhiều nguồn khác nhau dẫn đến việc nghiên cứu các giải pháp chuyển đổi, thu thập sẽ mất nhiều công sức và khả năng sai sót cao. Như vậy trước hiện trạng hiện nay đòi hỏi các nhà quản trị của công ty cần một hệ thống hỗ trợ tối đa trong việc tổng hợp toàn bộ dữ liệu, xử lý thành dạng có ý nghĩa, hữu ích và phân tích để từ đó đưa ra các báo cáo trực quan chính xác nhất, nhanh nhất đáp ứng nhu cầu ra quyết định của các cấp quản lý. Để giải quyết bài toán, tác giả đề xuất mô hình nghiên cứu xây dựng giải pháp BI hỗ trợ ra quyết định trong KTQT (Hình 5).

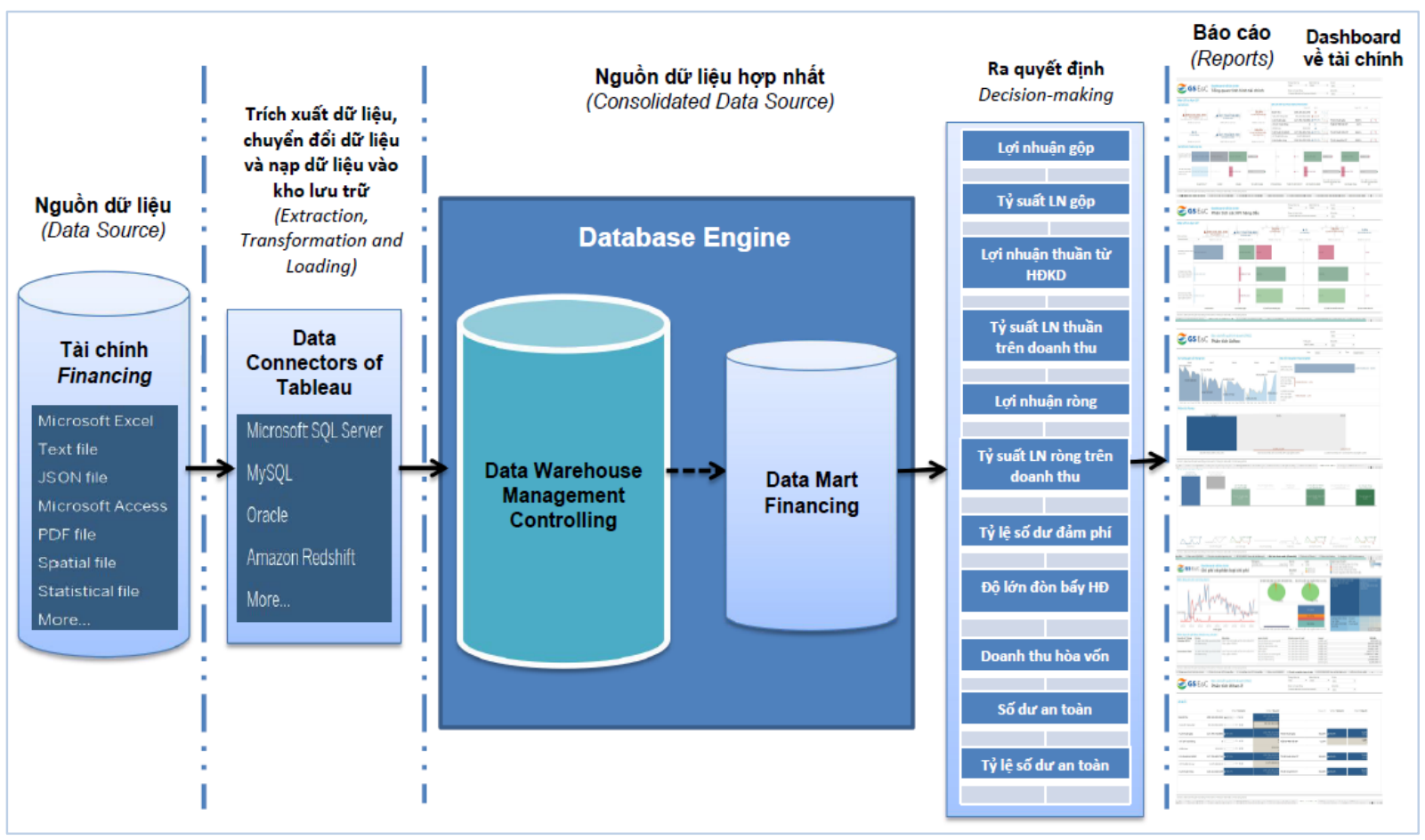

Hình 5. Mô hình nghiên cứu giải pháp hệ BI hỗ trợ ra quyết định trong KTQT

Nhận thức được vai trò quan trọng của chỉ số KPIs là công cụ giúp các nhà quản trị điều hành hoạt động của doanh nghiệp đáp ứng mục tiêu chiến lược đặt ra, trên cơ sở những đóng góp ý kiến của nhà quản trị và quá trình khảo sát cũng như phân tích định tính, tác giả đề xuất 
xây dựng chỉ số KPIs quan trọng về tài chính, cụ thể là báo cáo kết quả hoạt động kinh doanh (HĐKD) (Bảng 2).

\section{Bảng 2}

Chỉ số KPIs về tài chính được đề xuất cho mô hình

\begin{tabular}{|c|c|c|c|c|c|c|c|}
\hline Viễn cảnh & $\begin{array}{l}\text { Mục } \\
\text { tiêuu } \\
\text { chiến } \\
\text { lược }\end{array}$ & Chỉ số KPIs & ĐVT & $\begin{array}{l}\text { Mã } \\
\text { số }\end{array}$ & Công thức & $\begin{array}{l}\text { Trọng } \\
\text { số }\end{array}$ & $\begin{array}{c}\text { Chỉ } \\
\text { tiêuu } \\
2020\end{array}$ \\
\hline \multirow{11}{*}{$\begin{array}{l}\text { TÀl CHÍNH } \\
\text { (100\%) }\end{array}$} & \multirow{11}{*}{$\begin{array}{l}\text { Nâng } \\
\text { cao hiệu } \\
\text { quả kinh } \\
\text { doanh }\end{array}$} & Lợi nhuận gộp & Đồng & F1.1 & Doanh thu - Giá vôn hàng bán & $15 \%$ & 200 tỷ \\
\hline & & Tỷ suất lợi nhuận gộp & $\%$ & F1.2 & $\begin{array}{c}\text { Lợi nhuận gộp } \\
\text { Doanh thu }\end{array}$ & $8 \%$ & $29 \%$ \\
\hline & & Lợi nhuận thuần từ HĐKD & Đồng & F1.3 & Lợi nhuận gộp - Chi phí hoạt động - Khâuu hao & $12 \%$ & 200 tỷ ${ }^{*}$ \\
\hline & & $\begin{array}{l}\text { Tỷ suất lợi nhuận thuần } \\
\text { trên doanh thu }\end{array}$ & $\%$ & $\mathrm{~F} 1.4$ & $\begin{array}{c}\text { Lợi nhuận thuần từ HĐKD } \\
\text { Doanh thu }\end{array}$ & $10 \%$ & $29 \%$ \\
\hline & & Lợi nhuận ròng & đồng & F1.5 & Lợi nhuận thuần từ HĐKD - CP thuế và lãi vay & $15 \%$ & 185 tỷ \\
\hline & & $\begin{array}{l}\text { Tỷ suất lợi nhuận ròng trên } \\
\text { doanh thu }\end{array}$ & $\%$ & F1.6 & $\begin{array}{c}\text { Lợi nhuận ròng } \\
\text { Doanh thu }\end{array}$ & $10 \%$ & $27 \%$ \\
\hline & & Tỷ lệ số dư đảm phí & $\%$ & F2.1 & $\frac{\text { Số dư đảm phí }}{\text { Doanh thu }} \times 100 \%$ & $3 \%$ & $32 \%$ \\
\hline & & Độ lớn đòn bẫy hoạt động & & $\mathrm{F} 2.2$ & $\begin{array}{c}\text { Số dư đảm phí } \\
\text { Lợi nhuận }\end{array}$ & $2 \%$ & 1,1 \\
\hline & & Doanh thu hòa vốn & Đồng & $\mathrm{F} 2.3$ & $\frac{\text { Định phí }}{\text { Tỷ số số dư đảm phí }}$ & $12 \%$ & 63 tỷ \\
\hline & & Số dư an toàn & Đồng & $\mathrm{F} 2.4$ & Doanh thu thực hiện - Doanh thu hòa vốn & $3 \%$ & 634 tỷ \\
\hline & & Tỷ lệ số dư an toàn & $\%$ & $\mathrm{~F} 2.5$ & $\frac{\text { Số dư an toàn }}{\text { Doanh thu }} \times 100 \%$ & $10 \%$ & $91 \%$ \\
\hline
\end{tabular}

Nguồn: Kết quả phân tích dữ liệu của nhóm nghiên cứu

\section{Kết quả nghiên cứu}

\subsection{Hệ thống báo cáo về tài chính trong KTQT tại Công ty GS}

Trong phần thực nghiệm 4.2 dưới đây, nhóm tác giả phân tích và trực quan hóa kết quả phân tích KPIs cho một số báo cáo được chọn lọc từ Hệ thống báo cáo tài chính tại Hình 6 .

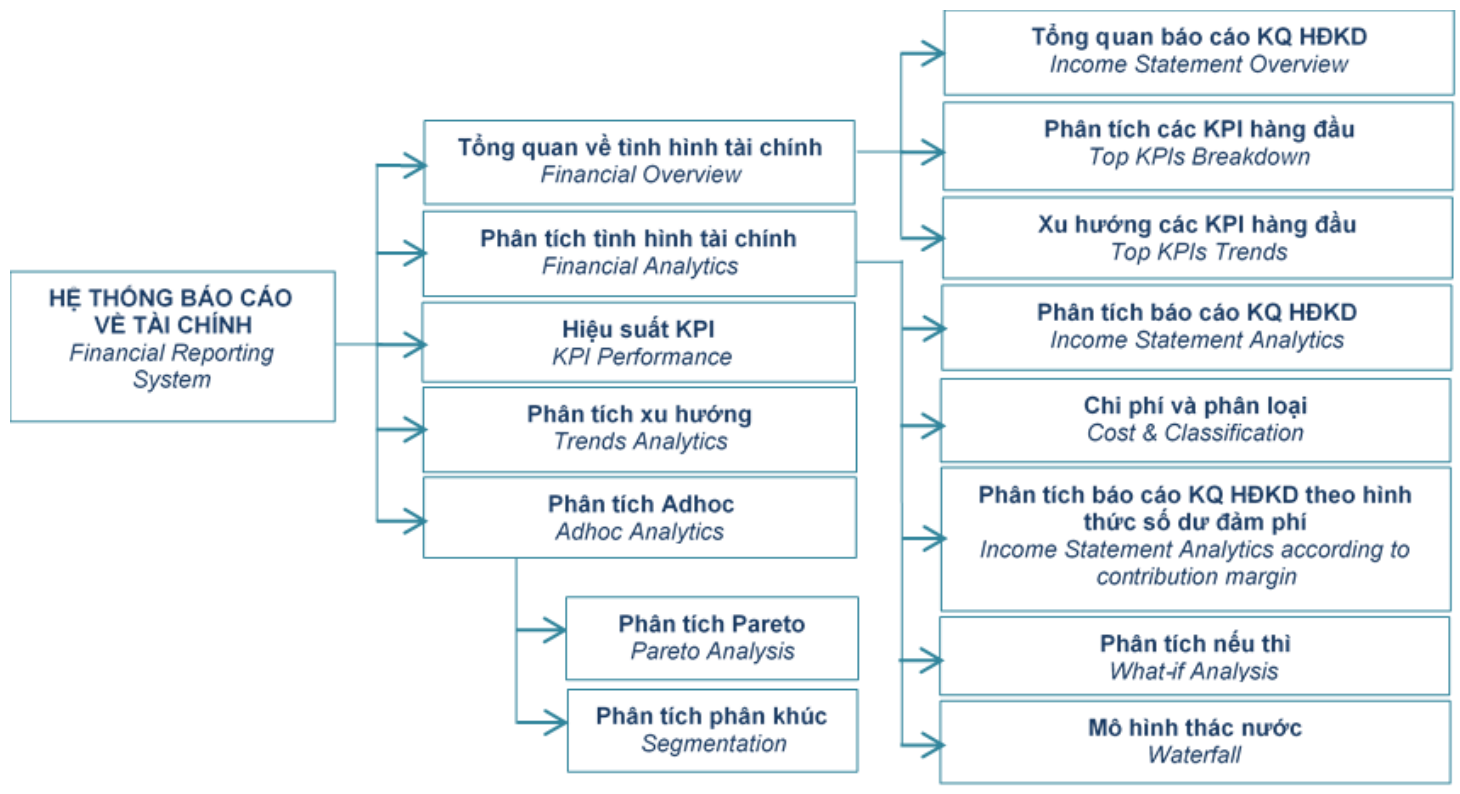

Hình 6. Hệ thống các báo cáo về tài chính trong nghiên cứu 


\subsection{Phân tích và trục quan dũ liệu trong $K T Q T$}

Để triển khai giải pháp, tác giả sử dụng hệ thống phân tích dữ liệu Tableau. Bởi Tableau là một trong những giải pháp phân tích và trực quan hóa dữ liệu đang phát triển nhanh nhất đang được sử dụng trong ngành $\mathrm{BI}$. Tableau đã thành công trong việc giữ vững vị trí trong top 3 các doanh nghiệp dẫn đầu trong báo cáo của (Gartner, 2018). Dashboard về tài chính được biểu diễn trực quan dưới đây cung cấp một cái nhìn tổng quan dễ hiểu về báo cáo kết quả HĐKD từ doanh thu đến lợi nhuận ròng, được phân tích thông qua các tỷ lệ hiệu suất có liên quan.

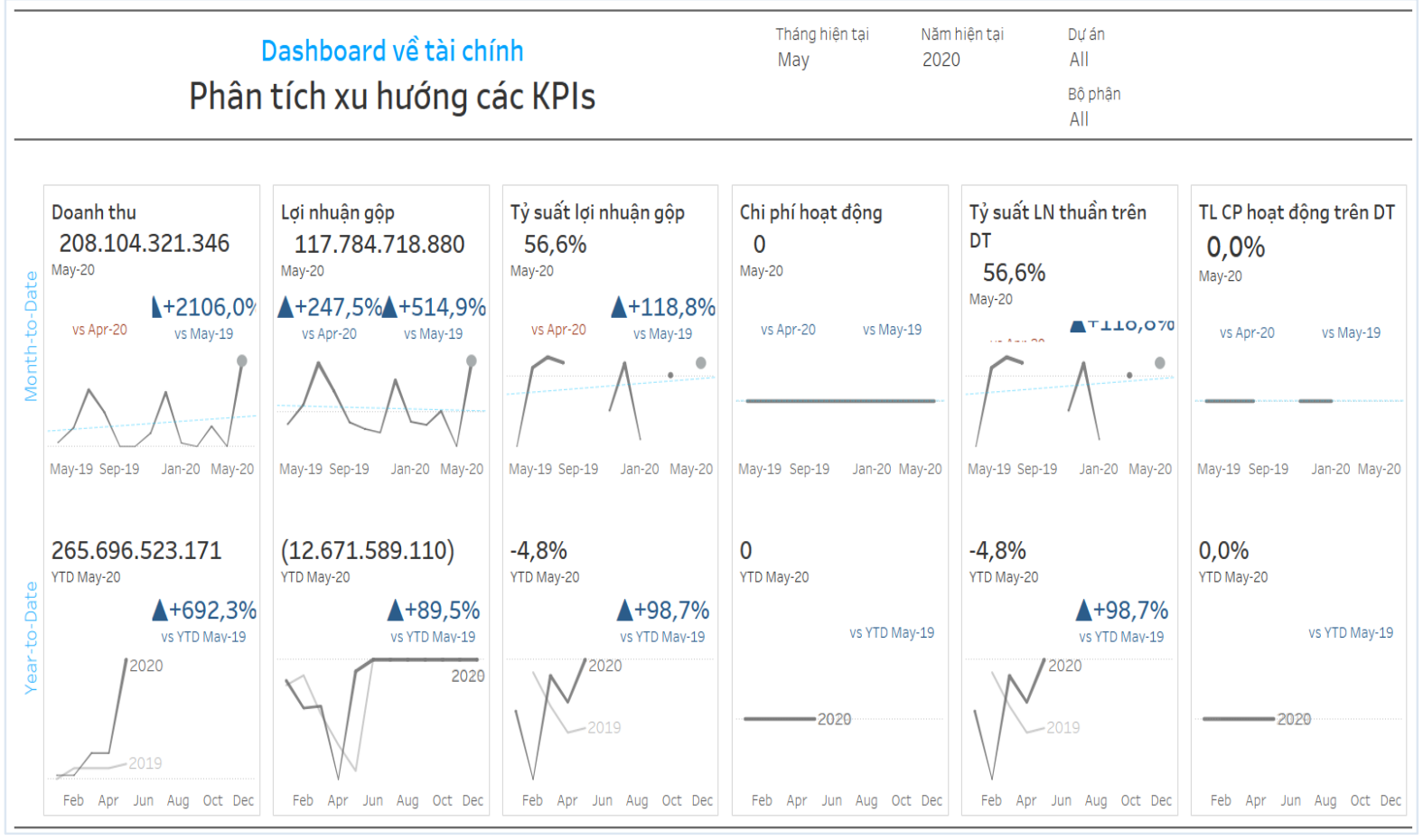

Hình 7. Phân tích xu hướng các KPIs

Xu hướng chỉ số KPIs hàng thứ nhất có sự biến động qua các năm. Tại thời điểm tháng 5/2020, tất cả chỉ số KPIs của công ty đều tăng trưởng khá cao so với cùng kỳ năm ngoái (Hình 7). Sở dĩ có sự khác biệt lớn như vậy là do tiến độ công việc của 2 dự án này đang ở giai đoạn cuối, nghiệm thu khối lượng hoàn thành các hạng mục còn lại. Tới cuối tháng 4, tiến độ dự án 2 đã đạt gần $72 \%$. 


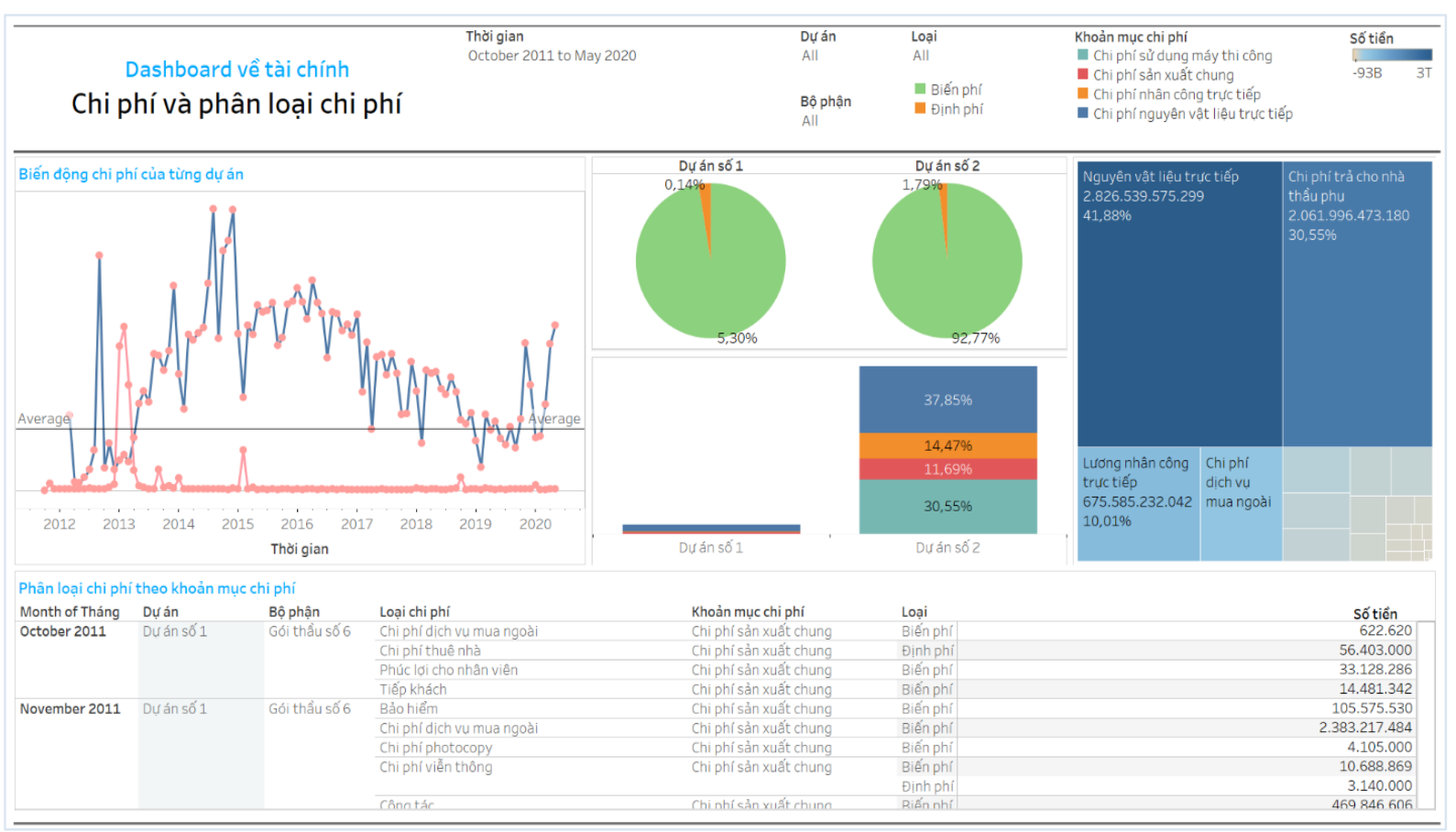

Hình 8. Chi phí và phân loại chi phí

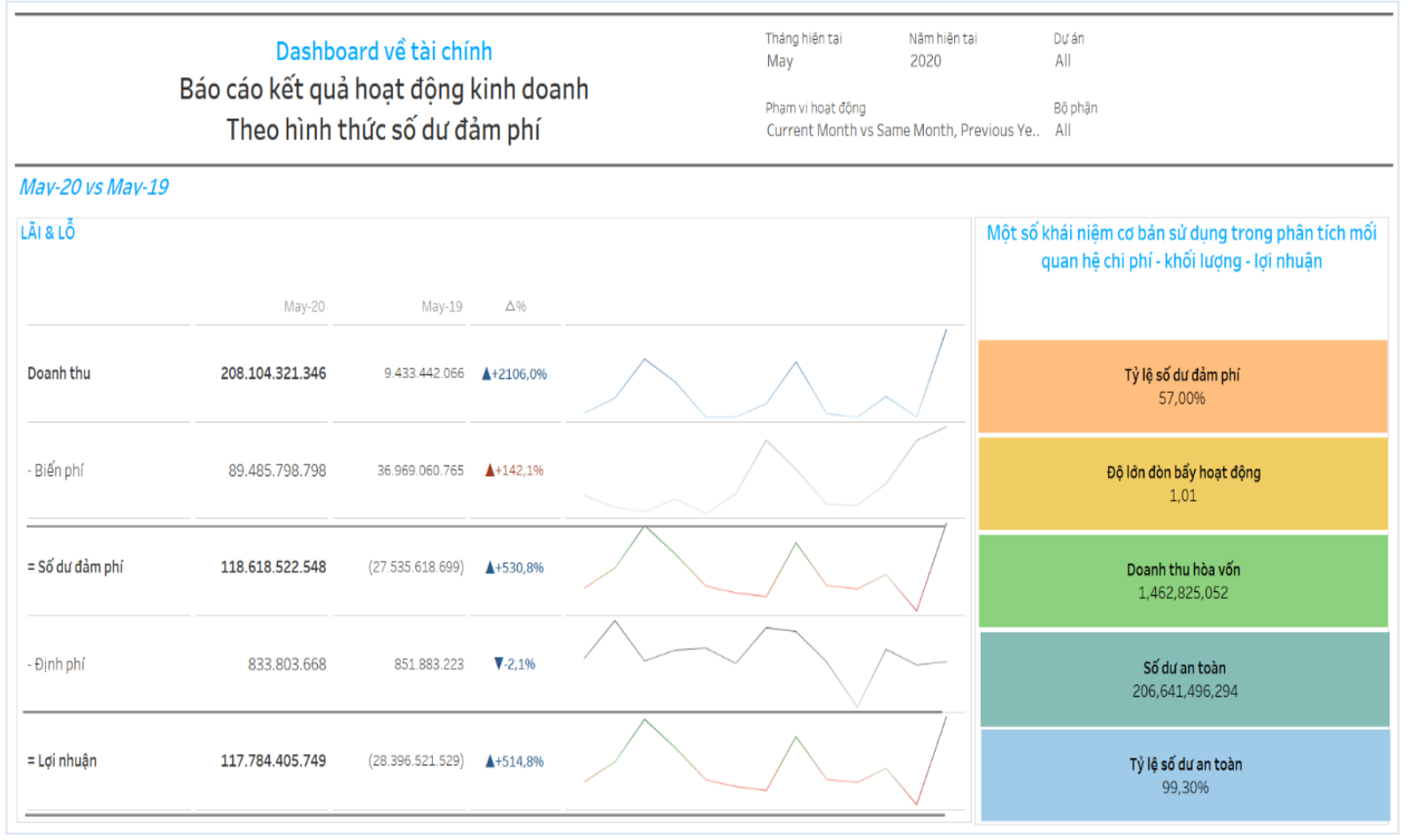

Hình 9. Báo cáo kết quả kinh doanh theo hình thức số dư đảm phí

Phân tích mối quan hệ chi phí - khối lượng - lợi nhuận (CVP) là xem xét mối quan hệ giữa giá bán, số lượng sản phẩm tiêu thụ, kết cấu hàng bán, biến phí, định phí và lợi nhuận, nhằm khai thác khả năng tiềm tàng của doanh nghiệp và là cơ sở để đưa ra các quyết định 
(Doan, Le, \& Dao, 2018). Doanh nghiệp có định phí chiếm tỷ trọng nhỏ, biến phí chiếm tỷ trọng lớn (Hình 8). Tỷ lệ số dư đảm phí là $57 \%$ (Hình 9). Trong đó, dự án 1 có tỷ lệ số dư đảm phí lớn 95,95\%; trong khi dự án 2 có tỷ lệ số dư đảm phí thấp hơn 52,77\%. Chứng tỏ, nếu tăng cùng một lượng doanh thu ở cả 2 dự án, dự án 1 có tỷ lệ số dư đảm phí lớn hơn thì lợi nhuận sẽ tăng lên càng nhiều hơn so với dự án 2 . Cả 2 dự án có độ lớn đòn bẩy hoạt động bằng 1 , như vậy giả sử trong điều kiện 2 dự án có cùng doanh thu và lợi nhuận, nếu tăng cùng 1 lượng doanh thu, dự án nào có đòn bẩy hoạt động lớn hơn thì lợi nhuận tăng lên nhiều hơn, vì vậy tốc độ tăng lợi nhuận sẽ lớn hơn. Chỉ số doanh thu hòa vốn tại tháng 5/2020 là 1,46 tỷ. Doanh thu hòa vốn là điểm hòa vốn của công ty mà tại đó tổng doanh thu bằng tổng chi phí hoặc tổng số dư đảm phí bằng tổng định phí. Chỉ số này là một nội dung quan trọng trong phân tích mối quan hệ CVP, giúp cho nhà quản trị xác định được doanh thu hòa vốn, từ đó xác định vùng lãi, vùng lỗ của doanh nghiệp. Bên cạnh đó, tỷ lệ số dư an toàn hiện tại khá cao 99,3\% chứng tỏ doanh nghiệp có độ an toàn trong kinh doanh cao.

\begin{tabular}{|c|c|c|c|}
\hline \multirow{2}{*}{$\begin{array}{c}\text { Báo cáo kết quả kinh doanh (P\&L) } \\
\text { Phân tích What-if }\end{array}$} & $\begin{array}{l}\text { Tháng hiện tại } \\
\text { May }\end{array}$ & $\begin{array}{l}\text { Nâm hiệntại } \\
2020\end{array}$ & $\begin{array}{l}\text { Dứán } \\
\text { All }\end{array}$ \\
\hline & \multicolumn{2}{|c|}{$\begin{array}{l}\text { Pham vi hoaat động } \\
\text { Current Month vs Same Month, Pre.. }\end{array}$} & $\begin{array}{l}\text { Bỗ phận } \\
\text { All }\end{array}$ \\
\hline
\end{tabular}

\begin{tabular}{|c|c|c|c|c|c|c|}
\hline \multicolumn{7}{|l|}{ PROFIT \& LOSS } \\
\hline & What-if Scenario & What-if May-20 & & May-20 & What-if Scenario & What-if May-20 \\
\hline Doanh thu & 208.104.321.346 $\mathbf{\Delta}+0,5 \%$ & $\begin{aligned} 209.144 .842 .953 \\
+1.040 .521 .607\end{aligned}$ & & & & \\
\hline - Giá vốn hàng bán & $90.319 .602 .466=$ & 90.319 .602 .466 & & & & \\
\hline = Lợi nhuận gộp & $117.784 .718 .880 \Delta+0,9 \%$ & $\begin{array}{r}118.825 .240 .487 \\
+1.040 .521 .607 \\
\end{array}$ & Tỷ suất lọi nhuận gộp & $56,6 \%$ & $+0,4 \%$ & $\begin{array}{r}56,8 \% \\
+0,2 \%\end{array}$ \\
\hline - Chi phíhoạt động & $0=$ & & Tỳ lệ CP H trên DT & $0,0 \%$ & & $0,0 \%$ \\
\hline -Khấu hao & $313.131=$ & 313.131 & & & & \\
\hline = LN thuần từ HDKD & $117.784 .405 .749 \Delta+0,9 \%$ & $\begin{array}{r}118.824 .927 .356 \\
+1.040 .521 .607\end{array}$ & Tỷ suất lọi nhuận thuần trên doa & $56,6 \%$ & $+0,4 \%$ & $\begin{array}{r}56,8 \% \\
+0,2 \%\end{array}$ \\
\hline -CP thuế \& lãi vay & $1.670 .383 .610=$ & 1.670 .383 .610 & & & & \\
\hline = Lợi nhuận ròng & $116.114 .022 .139 \Delta+0,9 \%$ & $\begin{array}{r}117.154 .543 .746 \\
+1.040 .521 .607\end{array}$ & Tỳ suất lọi nhuận ròng trên DT & $55,8 \%$ & $\Delta+0,4 \%$ & $\begin{array}{r}56,0 \% \\
+0,2 \%\end{array}$ \\
\hline \multicolumn{7}{|l|}{ PROFIT \& LOSS } \\
\hline & What-if scenario & What-if May-20 & & May-20 & What-if Scenario & What-if May-20 \\
\hline Doanh thu & $208.104 .321 .346=$ & 208.104.321.346 & & & & \\
\hline - Giá vốn hàng bán & $90.319 .602 .466 \quad \mathbf{\Lambda}+0,5 \%$ & $\begin{array}{r}90.771 .200 .478 \\
+451.598012 \\
\end{array}$ & & & & \\
\hline = Lọi nhuận gộp & $\begin{array}{lll}117.784 .718 .880 & -0,4 \% \\
\end{array}$ & $\begin{array}{r}117.333 .120 .868 \\
-451.598012 \\
\end{array}$ & Tỷ suất lọi nhuận gộp & $56,6 \%$ & $7-0,4 \%$ & $\begin{array}{r}56,4 \% \\
-0,2 \%\end{array}$ \\
\hline - Chi phí hoạt động & $0=$ & & Tỷ lệ CP HD trên DT & $0,0 \%$ & & $\begin{array}{r}0,0 \% \\
=\end{array}$ \\
\hline - Khấu hao & $313.131=$ & 313.131 & & & & \\
\hline$=L N$ thuẩn từ HDKD & $\begin{array}{ll}117.784 .405 .749 & 7-0,4 \% \\
\end{array}$ & $\begin{array}{r}117.332 .807 .737 \\
-451.598012 \\
\end{array}$ & Tỷ suất lọi nhuận thuần trên doan & $56,6 \%$ & $7-0,4 \%$ & $\begin{aligned} 56,4 \% \\
-0,2 \%\end{aligned}$ \\
\hline - CP thuế\& lãi vay & $1.670 .383 .610=$ & 1.670 .383 .610 & & & & \\
\hline = Lọi nhuận ròng & $\begin{array}{ll}116.114 .022 .139 & \nabla-0,4 \% \\
\end{array}$ & $\begin{array}{r}115.662 .424 .127 \\
-451.598012\end{array}$ & Tỷ suất lọi nhuận ròng trên DT & $55,8 \%$ & $7-0,4 \%$ & $\begin{array}{r}55,6 \% \\
-0,22 \%\end{array}$ \\
\hline
\end{tabular}

\section{Hình 10. Phân tích What-if}

Phân tích độ nhạy là dạng phân tích nhân quả nhằm trả lời cho câu hỏi “điều gì sẽ xảy ra... nếu như...." (what-if). Tác giả sử dụng phân tích này để xem xét yếu tố nào là quan trọng nhất hay yếu tố mang tính chất rủi ro ảnh hưởng đến kết quả của bài toán lợi nhuận. Nếu như tăng doanh thu lên $0,5 \%$, tương ứng doanh thu tăng 1,04 tỷ đồng thì lợi nhuận ròng sẽ tăng 
$0,9 \%$ và tỷ suất lợi nhuận ròng trên doanh thu tăng $0,2 \%$. Ngược lại, nếu như tăng giá vốn hàng bán lên $0,5 \%$, tương ứng giá vốn tăng 451,6 triệu đồng thì lợi nhuận ròng sẽ giảm $0,4 \%$ và tỷ suất lợi nhuận ròng trên doanh thu giảm $0,2 \%$ (Hình 10). Như vậy, cùng tăng một lượng như nhau $0,5 \%$, nhưng mức chênh lệch của lợi nhuận ròng là $0,5 \%(=0,9 \%-0,4 \%)$, do đó nhà quản trị của 2 dự án nên đưa ra quyết định tăng doanh thu bằng cách đẩy nhanh tiến độ thi công, nghiệm thu khối lượng hoàn thành các hạng mục, quy trình thanh toán trong giai đoạn tới. Trên mỗi dashboard này nhà quản trị có thể phân tích các KPIs theo từng bộ phận, từng dự án và theo thời gian để ra quyết định.

\section{Kết luận và hướng phát triển}

Nghiên cứu đã đề xuất giải pháp hệ BI và hỗ trợ ra quyết định trong KTQT. Thực nghiệm giải pháp cho trường hợp cụ thể với dữ liệu được thu thập từ nghiệp vụ KTTC và KTQT tại Công ty GS từ tháng 10/2011 đến tháng 5/2020 của dự án 1 và 2 tại Thành phố Hồ Chí Minh. Dữ liệu này có thể chưa phản ánh toàn diện tình hình tài chính của công ty nhưng làm đại diện để xây dựng giải pháp BI hỗ trợ ra quyết định trong KTQT. Kết quả đã cho thấy được giải pháp BI đề xuất đạt hiệu quả tốt. Với kết quả phân tích các KPIs và trực quan dữ liệu trên các dashboard về tài chính này, nhà quản trị có được những thông tin và tri thức quan trọng để theo dõi, ra quyết định đúng đắn và kịp thời. Với giải pháp BI, nhà quản trị có được công cụ dễ dàng xây dựng các dashboard; nghiên cứu đã xây dựng môi trường làm việc dựa trên dữ liệu và phân tích; sử dụng cho tất cả phòng ban và phù hợp với ngành nghề xây lắp; tốc độ phân tích dữ liệu nhanh; khả năng mở rộng độ lớn của dữ liệu theo thời gian một cách dễ dàng; chia sẻ \& bảo mật; kết nối và làm việc với nhiều loại dữ liệu cùng lúc; đáp ứng với các công nghệ Big Data, AI và khả năng tích hợp cao. Như vậy, giải pháp BI được đánh giá đã giải quyết được nhu cầu cấp bách của các nhà quản trị cấp cao tại Công ty GS trước thực trạng hiện nay nói riêng và khả năng mở rộng cho các lĩnh vực khác nói chung.

Hướng phát triển của nghiên cứu là sẽ đề xuất mở rộng triển khai giải pháp BI ở bộ phận thu mua, quản trị nguồn nhân lực, dòng tiền... cũng như tiếp tục phát triển mô hình và giải pháp cho nhiều loại hình doanh nghiệp khác. Đồng thời đề xuất thêm các KPIs tương ứng cho từng bộ phận và tích hợp thêm tính năng ứng dụng trên thiết bị di động để nhà quản trị dễ dàng phân tích dữ liệu và có được thông tin và tri thức khi cần.

\section{Tài liệu tham khảo}

AICPA. (2013). Strategic business management: From planning to performance. New York, NY: American Institute of Certified Public Accountants.

Appelbaum, D., Kogan, A., Vasarhelyi, M., \& Yan, Z. (2017). Impact of business analytics and enterprise systems on managerial accounting. International Journal of Accounting Information Systems, 25, 29-44.

Atkinson, A., Kaplan, R., \& Young, S. (2011). Management accounting (International edition). Upper Saddle River, NJ: Pearson Prentice Hall. 
Bộ Tài chính. (2006). Thông tu số 53/2006/ TT-BTC hướng dẫn áp dụng kế toán quản trị trong doanh nghiẹp [Circular No. 53/2006 / TT-BTC guiding the application of corporate governance accounting]. Retrieved March 30, 2020, from https://huvienphapluat.vn/van-ban/ke-toan-kiem-toan/Thong-tu-53-2006-TT-BTChuong-dan-ap-dung-ke-toan-quan-tri-doanh-nghiep-12534.aspx

Booth, P., Matolcsy, Z., \& Wieder, B. (2000). The impacts of enterprise resource planning systems on accounting practice - The Australian experience. Australian Accounting Review, 10(22), 4-18.

Bouquin, H. (2010). Management accounting in its social context: Rimailho revisited. Accounting, Business \& Financial History, 7(3), 315-343.

Chaudhuri, S., Dayal, U., \& Narasayy, V. (2011). An overview of business intelligence technology. Communications of the ACM, 54, 88-98.

Chen, H., Chiang, R., \& Storey, V. (2012). Business intelligence and analytics: From big data to big impact. MIS Quarterly, 36(4), 1165-1188.

Clark, T., Jones, M., \& Armstrong, C. (2007). The dynamic structure of management support systems: Theory development, research focus, and direction. MIS Quarterly, 31(3), 579615.

Cokins, G. (2009). Performance management: Integrating strategy. Execution, methodologies, risk, and analytics. Hoboken, NJ: Wiley.

Cox, R., Issa, R., \& Ahrens, D. (2003). Management's perception of key performance indicators for construction. Journal of Construction Engineering and Management, 129(2), 142151.

Deng, X., \& Chi, L. (2012). Understanding postadoptive behaviors in information systems use: A longitudinal analysis of system use problems in the business intelligence context. Journal of Management Information Systems, 29(3), 291-326. doi:10.2753/MIS07421222290309

Doan, N. Q., Le, D. T., \& Dao, T. T. (2018). Giáo trình Kế toán quản trị [Management Accounting textbook]. Ho Chi Minh, Vietnam: Đại học Kinh tế Thành phố Hồ Chí Minh.

Eisenhardt, K. (1989). Building theories from case study research. Academy of Management Review, 14(4), 532-550.

Elbashir, M. Z., Collier, P. A., \& Sutton, S. (2011). The role of organizational absorptive capacity in strategic use of business intelligence to support integrated management control systems. The Accounting Review, 86(1), 155-184.

Gartner. (2018). Tableau named a leader in the Gartner Magic Quadrant for six years in a row. Retrieved March 20, 2020, from https://www.tableau.com/about/blog/2018/2/tableaunamed-leader-gartner-magic-quadrant-six-years-row-82534

Gounder, M. S., Iyer, V. V., \& Mazyad, A. A. (2016). A survey on business intelligence tools for university dashboard development. Proceedings of 2016 3rd MEC International Conference on Big Data and Smart City, 85-91. 
Harrison, G. (1992). The cross-cultural generalizability of the relation between participation, budget emphasis and job related attitudes. Accounting, Organizations and Society, 17(1), $1-15$.

Ho, T. T., Ho, T. P. T., Le, T. T., Le, H. P. K., \& Tran, T. T. N. (2016). Cloud ERP, a new approach for enterprise resources planning. Science and Technology Development Journal, 19(1), 111-128. doi:10.32508/stdj.v19i1.532.

Jonathan, W. (2000). Business intelligence: What is business intelligence? Retrieved March 15, 2020, from http://www.dmreview.com/article_sub.cfm?articleId=1924

Kaario, K., \& Peltola, T. (2008). Tiedonhallinta: Avain tietotyön tuottavuuteen. Porvoo, Finland: WS Bookwell.

Kaplan, R. (1994). Management accounting (1984-1994): Development of new practice and theory. Management Accounting Research, 5(3-4), 247-260.

Kerzner, H. (2011). Project management metrics, KPIs, and dashboards: A guide to measuring and monitoring project performance. Hoboken, NJ: John Wiley \& Sons, Inc.

Langfield-Smith, K. (2006). A review of quantitative research in management control systems and strategy. Handbooks of Management Accounting Research, 2, 753-783.

Laudon, K. C., \& Laudon, J. P. (2018). Enhancing decision making. In Management information systems, managing the digital firm (pp. 452-484). New York, NY: Pearson.

Maisel, L., \& Cokins, G. (2014). Predictive business analytics: Forward looking capabilities to improve business performance. Hoboken, NJ: John Wiley \& Sons, Inc.

Neely, P., \& Cook, J. (2011). Fifteen years of data and information quality literature: Developing a research agenda for accounting. Journal of Information Systems, 25(1), 79108.

Nguyen, B. N. (2017). Nghiên cứu vấn đề đo lường thành công của dự án xây dựng và đề xuất sử dụng KPIs [Study the issue of measuring the success of a construction project and proposing the use of KPIs]. Tạp chí Kinh tế Xây dụng, 4, 1-9.

Nguyen, D. T. (2013). Giáo trình phương pháp nghiên cúu khoa học trong kinh doanh [Curriculum scientific research methodology in business]. Ho Chi Minh, Vietnam: Nhà xuất bản Tài Chính.

Nguyen, Q. T. (2017). Vai trò của thông tin kế toán quản trị với việc ra quyết định của nhà quản trị doanh nghiệp [The role of management accounting information with corporate governance decision-making]. Tạp chí Công thuoong, 8, 401-406.

O'Connor, N. (1995). The influence of organizational culture on the usefulness of budget participation by Singaporean-Chinese managers. Accounting, Organizations and Society, 20(5), 383-403.

Ogunsanmi, O. (2013). Stakeholders' perception of key performance indicators (KPIs) of public-private partnership (PPP) projects. International Journal of Construction Supply Chain Management, 3(2), 27-38. 
Olivia, R. (2009). Business intelligence success factors: Tools for aligning your business in the global economy. Hoboken, NJ: Wiley \& Sons Inc.

Otley, D. (1980). The contingency theory of management accounting: Achievement and prognosis. Accounting, Organizations and Society, 5(4), 413-428.

Pall, R., \& Ogan, Y. (2018). Business intelligence \& analytics in management accounting research: Status and future focus. International Journal of Accounting Information Systems, 29(c), 37-58.

Parmenter, D. (2009). KPI - Các chi số đo luờng hiệu suất [KPIs - Indicators that measure performance] (T. T. K. Nguyen, Trans.). Ho Chi Minh, Vietnam: Nhà xuất bản Tổng hợp.

Patton, M. (1990). Qualitative evaluation and research methods. Newbury Park, CA: Sage.

Phillips, J. (2013). Building a digital analytics organization: Create value by integrating analytical processes, technology, and people into business operations. London, UK: Pearson FT Press.

Pirttimäki, V. (2007). Business intelligence as a managerial tool in large Finnish companies. Tampere, Finland: Tampere University of Technology.

Popovic, A., Turk, T., \& Jaklic, J. (2010). Conceptual model of business value of business intelligence systems. Journal of Contemporary Management Issues, 15(1), 5-29.

Rick, Y. (2017). Business intelligence and analytics - From A to Z (Part 1). Retrieved March 22, 2020, from https://blog.trginternational.com/vi/thuat-ngu-business-intelligenceanalytics-from-a-to-z

Romano, C. (1989). Research strategies for small business: A case study. International Small Business Journal, 7(4), 35-43.

Salminen, J. (2005). Measuring performance and determining success factors of construction sites. Espoo, Finland: Helsinki University of Technology Construction Economics and Management.

Schneider, G., Jun Dai, Janvrin, D., Ajayi, K., \& Raschke, R. (2015). Infer, predict, and assure: Accounting opportunities in data analytics. Accounting Horizons, 29(3), 719-742.

Volitich, D., \& Ruppert, G. (2012). IBM cognos business intelligence 10: The official guide. New York, NY: McGraw-Hill.

Waterhouse, J., \& Tiessen, P. (1978). A contingency framework for management accounting systems research. Accounting, Organizations and Society, 3(1), 65-76. 